\title{
Transcranial Theory of Mind: A New Revolution of Cognitive Science
}

\author{
Li Jianhui \\ School of Philosophy, Beijing Normal University, Beijing, China \\ Email address: \\ ljh@bnu.edu.cn \\ To cite this article: \\ Li Jianhui. Transcranial Theory of Mind: A New Revolution of Cognitive Science. International Journal of Philosophy. \\ Vol. 7, No. 2, 2019, pp. 66-71. doi: 10.11648/j.ijp.20190702.14
}

Received: April 17, 2019; Accepted: June 4, 2019; Published: June 17, 2019

\begin{abstract}
In recent years, many scientists and philosophers have begun to believe that a new theoretic revolution is occurring in cognitive science. The revolution is the rise of theoretical models of " $4 \mathrm{E}+\mathrm{S}$ " cognition. "4E" denotes "embodied", "embedded", "enacted", and "extended"; "S" denotes "situated". Differentiating from the traditional computational theory or representational theory of cognition, this branch of new cognitive scientists and philosophers have begun to claim that cognition is embodied, embedded, enacted, extended and situated. All of these five theories agree that cognitive processes can proceed beyond the boundary of the brain. Thus we can synthesize them together as "transcranial cognition" or "transbrain cognition". The questions are: Are there common characteristics of these five models? Can we integrate them together with a new model of cognition? Is the " $4 \mathrm{E}+\mathrm{S}$ " model a real Copernicus style revolution of cognitive science? This article analyzes these questions and provides the following answers: There is a common characteristics of these cognitive theories and it is the characteristics of transcranialness, i. e. cognition or mind can exist beyond brain; We can integrate them together as transcranial cognition; The new theory of cognition or mind is a new big extended theory of traditional cognitive science.
\end{abstract}

Keywords: Transcranial Cognition, 4E+S Cognition, Embodied Cognition, Embedded Cognition, Enacted Cognition, Extended Cognition, Situated Cognition

\section{Introduction}

In recent years, many philosophers and cognitive scientists have begun to believe that a new theoretic revolution is occurring in cognitive science. The revolution is the rise of theoretical models of " $4 \mathrm{E}+\mathrm{S}$ " cognition. " $4 \mathrm{E}+\mathrm{S}$ " refers to embodied mind, embedded mind, enacted mind, extended mind, and situated mind. Embodied mind is the idea that not only the brain is responsible for cognition but that our body also has an important role in the formation of cognition. That is, some bodily processes outside the brain may participate in cognitive processes. As Rowlands says in his new book, New Science of Mind, embodied mind means "mental processes... are partly constituted by, partly made up of, wider (i.e., extraneural) bodily structures and processes" [1]. Embedded mind refers to the idea that a cognitive subject is embedded in the environment and cannot be separated from it. It is believed that some environmental processes outside of the body may be constitutive parameters for completing cognitive tasks. Rowlands generalized this idea as follows: "mental processes... have been designed to function only in tandem with a certain environment that lies outside the brain of the subject" [1]). Enacted mind is the idea that an organism's interaction with its environment may be an integral part of its cognitive system. As Rowlands characterizes this idea, mental processes are composed of not just the process of neurons, but also the other events the organism does more generally: "They are constituted in part by the ways in which an organism acts on the world and the ways in which the world, as a result, acts back on that organism" [1]. Extended mind theorists hold that mental processes are not just located inside an organism's brain, but extend out into the environment of the organism [1]. This means that a cognitive process may be extended beyond the organism's brain. Situated mind is the idea that our cognition is situated in a specific context. Cognition (systems, capacities, functions, and processes) is situated or contextually defined and dependent. The location may be in the brain, but it may also be in the body and even in the environment beyond the body.

The $4 \mathrm{E}+\mathrm{S}$ mind is rooted in a variety of scientific fields, such as dynamic approaches to cognitive and developmental 
psychology, situated robotics and artificial intelligence, an ecological approach to perceptual psychology, and cognitive neuroscience. There are also some philosophical inspirations of $4 \mathrm{E}+\mathrm{S}$ cognition, such as Humean empiricism, phenomenology and pragmatism. According to Humean empiricism, the mind is nothing but an aggregate of mental states and processes. This is different from Descartes' bare substratum notion: the mind is something that contains or has mental states such as beliefs, desires, ideas, and thoughts, and mental acts and processes such as perceiving, thinking, and reasoning. Humean empiricism is one source of $4 \mathrm{E}+\mathrm{S}$ cognition. Another philosophical source of $4 \mathrm{E}+\mathrm{S}$ cognition is phenomenology. For example: "embodied" can be traced to the tradition of phenomenology of Merleau-Ponty. Merleau-Ponty thinks that the lived body should be the starting point for the philosophical study of cognition.

At the end of twentieth century and beginning of the twenty-first century, an increasing number of books and papers were published on the specific topics of "4Es" and " $S$ ". The most influential publications are Varela, F., \& Thompson, E., \& Rosch, E. (1991); Clark, A., \& Chalmers, D. (1998); Lakoff, G., \& Johnson, M. (1999); Noë, A. (2004); Adams, F., \& Aizawa, K. (2008); Aydede, M. (Eds.) (2009); Rowlands, Mark (2010); Shapiro, Lawrence (2011); Stewart, J., O. Gapenne, \& E. Di Paolo (2011); Hutto, D. \& E. Myin (2013) and Hutto, D. \& E. Myin (2017); Colombetti, G. (2013); Radman, Z. (2013); Huebner, B. (2014); Cappuccio, M \& T. Froese (2014); Johnson, Mark (2017); Gallagher, Shaun (2017); Jasanoff, Alan (2018) [1-18].

With the development of these new trends of cognitive science, philosophers begin to coin the expressions "4E" and “4E+S". In 2007, Shaun Gallagher organized a truly rewarding interdisciplinary conference called " $4 \mathrm{e}$ : The Mind Embodied, Embedded, Enacted, Extended" at the University of Central Florida. This was the first time philosophers referred to different trends of cognitive studies as "4E". In 2012, Zhaolu $\mathrm{Lu}$, from Tiffin University, coined the word " $4 \mathrm{E}+\mathrm{S}$ " cognition in a series of lectures in Beijing Normal University organized by Jianhui Li. The common characteristics of this new trend of cognitive science was discussed and later a new synthetic name: "transcranial cognition (or mind)" or "transbrain cognition (or mind)" was coined.

There are also some journal special issues discussing $4 \mathrm{E}+\mathrm{S}$. In 2009, Julian Kiverstein and Andy Clark edited special issues about "the enacted mind and the extended mind" in Topoi (Volume 28, Number 1 / March 2009)[19]. In 2010, Richard Menary edited "4E Cognition: Embodied, Embedded, Enacted, Extended" in Phenomenology and the Cognitive Sciences (Volume 9, Number 4 / December 2010) [20].

Now the $4 \mathrm{E}+\mathrm{S}$ cognition is quite influential in contemporary discussion about cognitive science. However, there are many questions needed to answer, such as: What is the central idea of $4 \mathrm{E}+\mathrm{S}$ cognitions? Or what are the common characteristics of these five models? Can we integrate them together with a new model of cognition? Is the $4 \mathrm{E}+\mathrm{S}$ models a real Copernican revolution or not? We will answer these questions in this paper.

\section{The Central Idea of Transcranial Cognition}

Though there are differences among these five models, the central idea of them is the same: Our mind is not just in our brain, it can be beyond the brain. With the development of cognitive science, the location of the mind has become a hot topic in the contemporary philosophy of cognition and the mind. Philosophers of cognition always ask the following questions: "Where is the location of our mind?" "Where does the mind end and rest of the world begin"? "Where does your mind begin, and where does it end" [1]?There are two views for answering these questions: "in brain" or "beyond brain".

In the beginning of modern philosophy, Descartes thought that the mind is in the brain. According to Descartes, minds do not have a spatial extension, but they do have a spatial location. Every mind is located somewhere in the vicinity of the brain's pineal gland. Today, people do not believe that the mind is in the vicinity of the pineal gland, but many believe that the mind is in the brain. If we take contemporary science seriously, we may find that scientists are mainly materialists. They believe that mental properties are properties of the brain and mental processes-perceiving, remembering, thinking, reasoning, and so on-exist only in the brain. The mind is identical with, or exclusively realized by, the brain. Thus, the mind has a fixed size and location - namely, it is in the brain and cannot be extended beyond the brain.

With the development of $4 \mathrm{E}+\mathrm{S}$ cognitive science, some philosophers have begun to believe that the location of cognition and the mind are not just in the brain. They can be extended outside of the brain. As Rowlands says, "Cognitive tasks are not, in general, the sort of thing that need be accomplished only in the head or by a brain" [1]. In general, the mind does not have a fixed size and may extend beyond the brain. Some of the philosophers say that the mind is embodied, some of them say it is extended, some of them say it is embedded, some of them say it is exacted, and some of them say it is situated. According to these sayings, the location of the mind can be in the body and in the environment. In other words, the mind is a complex set of states, processes, and activities distributed across the brain, body, and world. Mental states, processes, and activities may happen inside our brains, but they may also happen, partly, in our bodies outside our brains, and they may even happen, partly, in the world outside our bodies. This is why we also call $4 \mathrm{E}+\mathrm{S}$ cognition "transcranial cognition" and "transbrain cognition".

\section{Can We Integrate " $4 \mathrm{E}+\mathrm{S}$ " Cognition Together with a New Model of Cognition}

As Richard Menary said: “One reason that the four E's are grouped together is that they are all held to reject or at least 
radically reconfigure traditional cognitivism, coupled with a methodological individualism" [19]. However, "homogeneity there is not" [16]. For example, enactivism, as understood by Thompson (2007), Thompson and Stapelton (2009) and DiPaulo (2009), is a thesis about the continuity between life and the mind. However, Noë understands "enactive" as a viewpoint in which perception is a skillful activity by which we probe the world for information. Like any skillful activity, it requires know-how. Noë calls the kind of knowledge that is required for perception sensorimotor knowledge. Thus, Menary says:

"One might conclude that there is no homogeneity within 4E cognition, except a shared enemy-cognitivism. Even this claim turns out to be too strong. Some extended mind theorists, such as Clark and Sutton, are quite happy to endorse a weak cognitivism - that representations are sometimes involved in cognition. Whereas some enactivists are much more radical, calling for the replacement of cognitivism and arguing that there is no need at all for mental representations in cognitive explanations or that they will have a very limited and reduced role" [20].

As we see, in $4 \mathrm{E}+\mathrm{S}$, there are diverse attitudes towards the mainstream: functionalism is accepted by some $4 \mathrm{E}+\mathrm{S}$ scholars, computationalism is rejected by most $4 \mathrm{E}+\mathrm{S}$ scholars, representationalism is rejected by many $4 \mathrm{E}+\mathrm{S}$ scholars but accepted by others, formalism is rejected by nearly all $4 \mathrm{E}+\mathrm{S}$ scholars, and solipsism is rejected by all $4 \mathrm{E}+\mathrm{S}$ scholars.

When first proposing $4 \mathrm{E}+\mathrm{S}$ cognition, cognitive scientists and philosophers tried to define the exact meaning of their new cognitions. The most important thing for them was to differentiate their new ideas from the old ones. However, with the development of these ideas, they began to try to find similarities between the different cognitions. As Julian Kiverstein and Andy Clark say:

"Given this large surface diversity, it seems fair to ask what, if anything, forms the deep theoretical core of the embodied, embedded approach? Equally importantly, we may ask to what extent the various projects pursued under the single umbrella are in fact harmonious" [19]?

Actually, we find that there is common ground between the $4 \mathrm{E}+\mathrm{S}$ cognitions. For example, all $4 \mathrm{E}+\mathrm{S}$ scholars emphasize that body, environment, and interaction between brain, body and environment are important for cognition and the mind. Concerning the body, all $4 \mathrm{E}+\mathrm{S}$ scholars endorse some kind of embodiment view. Concerning the environment, some $4 \mathrm{E}+\mathrm{S}$ scholars endorse the environment extension view. In terms of interaction, nearly all $4 \mathrm{E}+\mathrm{S}$ scholars adopt some kind of interaction approach.

Rowlands is an important philosopher who was first to try to integrate $4 \mathrm{E}+\mathrm{S}$ together. He synthesized them together as "the amalgamated mind". His method was to abstract the central idea of $4 \mathrm{E}+\mathrm{S}$ and find that this idea is counter to the traditional Cartesian view of cognition. Cartesian cognitive scientists maintain that all mental processes must happen exclusively inside the brain of the organism. While the scientists of the new trends of cognitive science or non-Cartesian cognitive science emphasize that the mind (mental states, processes, events and activities) is not bound to the brain and it can extend beyond the border of the brain. Because the mind and cognition are amalgamated with the brain, the body, the environment and their relations, Rowlands integrates all the non-Cartesian conceptions of the mind together as the amalgamated mind.

However, this non-Cartesian conception of the mind, which Rowlands calls the amalgamated mind, only integrates embodied mind and extended mind. The notions of the enacted mind and the embedded mind are excluded. The embedded mind emphasizes the importance of environment, but does not claim that mental processes can be extended beyond the brain, and thus is excluded. The enactive mind emphasizes the interrelation of the subject of cognition and environment, but does not claim cognition can be beyond human brain, and thus is excluded. Therefore, the amalgamated mind is the integration of the embodied mind and the extended mind.

Why can the embodied mind and extended mind be integrated as amalgamated mind? How can extraneural processes be cognitive? Rowlands' first strategy is to define what is the indication of cognition. Or more clear speaking, his first strategy is to specify a set of sufficient conditions for a process which can be called cognitive process. According to Rowlands, there are four sufficient conditions for cognition. A process can be called cognition if:

(1) it manipulates and transforms information for its subject;

(2) it has the proper function of making information available to its subject;

(3) it produces a representational state in its subject;

(4) it belongs to or is owned by its subject. [1]

The key point here is that each of these conditions refers to a subject. Where an informational process is located is not essential for it to be cognitive. What is essential is that the information process must belong to a cognitive subject.

How does an information process belong to a cognitive subject? Rowlands' answer is that it does so only if it is intentional.

Thus, Rowlands' second strategy is to propose a new theory of intentionality. Rowlands defines intentionality as a process of revelation or a disclosure of the mind.

Intentionality is a hard problem in the philosophy of the mind. As we already know, intentionality is a characteristic of the mind. We always say that intentionality is propositional; it is directed, it is aspectual, and it is representational. However, how do we further interpret the essence of intentionality? Rowlands interprets intentionality as a revealing process: "A subject's experience is directed at an object," which means that "the object is revealed to the subject." According to this interpretation, our experience or belief produced by our mind is actually a revealing process. Why do we experience something? It is because something is revealed in our mind. Why do we intend something? It is also because something is revealed. However, what is the mechanism of the revealing process? Rowlands says that the revealing process is a dual-mode process: the empirical mode and transcendental 
mode. The empirical mode means that the content is revealed and experienced. This is something of which the subject is aware. Our mind experiences the content. The transcendental mode means that the vehicle that carries the content - the set of causal processes that make the experience possible. This is something of which the subject is not aware.

Making these classifications, Rowlands begins to reinterpret intentionality. He thinks that intentionality is a revealing process, which means that the object in the world is revealed by the intentional subject as an experience. That means, our mind is a two-mode process: transcendental mode and experience mode. In the transcendental mode, we do not experience the mental processes, while in the experience mode, we do experience the mental processes. This understanding of intentionality gives a dualistic characterization of the mind. The transcendental mode of intentionality is a causal process while the experience mode of intentionality is phenomenal. The transcendental revelation of the world is the base of the empirical revelation of the world.

How can our mind be embodied and extended to our body and to the environment? Based on this new understanding of intentionality, Rowlands tries to integrate the $4 \mathrm{E}$ minds. If a process falls into the experience mode, it is the mind, and if a process falls into the transcendental mode, it is also the mind. Therefore, if the process of a subject is under the transcendental mode, though the subject does not experience it, it is also a mental process. Embodied processes and the extended process of the mind are all mental processes because they all fall into the transcendental mode of the mind. Rowlands thus integrates embodied and extended minds as transcendental modes of revealing. As we know, those causal processes that constitute the transcendental mode of revealing are not necessarily located in the brain. Many of them are in the outside world. Therefore, Rowlands holds, in principle, that a cognitive process can extend beyond the brain and beyond the body.

Rowlands' integration seems good, but the problem is: Though the transcendental revelation of mind may extend well enough beyond the brain and into the world, the explanatory gap between the world and mind still remains. The core revelation, i.e., the experience mode of mind, is still in one's head.

\section{Is the "4E+S" Model a Real Copernican Revolution}

As the title of Rowlands' book, New Science of Mind, shows, many philosophers think that $4 \mathrm{E}+\mathrm{S}$ cognitions are now forming a new science of the mind: a new revolution of cognitive science. Relative to the Cartesian tradition of cognitive science, the revolution of $4 \mathrm{E}+\mathrm{S}$ is of the Copernicus style. However, is this a real Copernicus style revolution in cognitive science? To see this, we need to evaluate the central idea of the $4 \mathrm{E}+\mathrm{S}$ cognitions.

To borrow from Shapiro [8], there are three theses for transcranial cognition: conceptualization thesis, replacement thesis, and constitution thesis.

The "conceptualization thesis" is the hypothesis that an organism's body is an important element to determine the concepts the organism can acquire. It posits that organisms with different bodies conceive of the world differently. In order for A to conceive of the world as B does, A must have a body such as B's [8].

The "replacement thesis" means that in the transcranial cognition, the important things are not the representational processes, but "the dynamics of an organism's bodily interaction with the environment". Thus, cognition can be explained without the appeal to representational states or computational processes. It is a functional property of a synergistic system between an organism and its environment. This hypothesis receives support from research projects that are inspired by ecological psychology, dynamical system theory, and investigations of autonomous robots [8].

The "constitution thesis" says that the body or world are constituents of cognition. It can be extended beyond the brain. It is a commitment to the idea that bodily properties, which claimed to be the determining factors of conceptualization, and synergistic functions, are important and genuine constituents of cognitive processes [8].

Which one is the better theory of cognition? Transcranial cognition or traditional standard cognitive science? Shapiro's evaluation is as follows:

"Conceptualization competes with standard cognitive science and loses. Replacement competes with standard cognitive science and wins in some domains, but likely loses in others. Constitution does not compete with standard cognitive science, but pushes it to extend its boundaries further than many of its practitioners would have anticipated." [8].

Why does the "conceptualization thesis" lose? Shapiro doubt the explanation of the conceptualization thesis. In his book, he gives an example from Varela, Thompson and Rosch (1991) to illustrate this. Varela et al. argues that different organisms will have different color experiences because they have different kinds of visual systems. But Shapiro thinks that this explanation is something of a triviality because what the thesis predicts the traditional cognitivist would also predict [2] Thus, Shapiro concludes that the "data that impress proponents of Conceptualization might as well, or better, be accounted for within the framework of standard cognitive science" [8].

Where does "replacement" win and where does it lose? The replacement thesis is based on the belief that cognition is not constraint in the brain but emerge from the interactions between human's brain, body, and world. Thus a cognizing agent need to continuously interact with the world. It does not need to represent status of the outside world [8]. As we know, the so called standard cognitive science is based on representation. If representation is not needed for cognitive systems, the standard cognitive science will be in danger. Thus Shapiro says if replacement thesis is right, it will raise "perhaps the most serious challenge to standard cognitive 
science" [8]. However, Shapiro does not want to simply replace the standard "representationalist" version of cognition. He thinks that the replacement thesis actually is not right in all situation. Of course, in certain kinds of cognitive activities, the cognizing agent does not need representations. However, in some other cognitive activities, such as human abstract thinking, problem solving, language processing, and advanced planning, the cognizing agent surely does [8]. Thus, Shapiro concludes that replacement thesis is true in certain cognitive phenomena, but is not true in some other cognitive phenomena [8].

For the constitution thesis, Shapiro believes that it does not compete with standard cognitive science. The constitution hypothesis states that in cognitive activities, the cognitive agent's body and his environment may play a constitutive role in cognitive processing [8]. But this constitutive role is not to replace the representational and computational core of traditional cognitive science, but only "to push it further, revealing how it might actually enhance our understanding of systems in which brain, body, and world are knotted together" [8].

From Shapiro's conclusion, transcranial cognition does not provide a true revolution in cognitive science. However, is it true? Are there flaws in Shapiro's conclusion?

Kristian Moltke Martiny [21] does not agree with Shapiro. He argues that Shapiro neglects some important ideas that support transcranial cognitions. According to Martiny [21], one of Shapiro's failures is that he neglects the influence of phenomenology on embodied cognition. He says that in Shapiro's book, phenomenology does not take seriously. Shapiro mentions phenomenology, but only mentions in passing. Even some influential phenomenologists, such as Husserl and Merleau-Ponty, are not mentioned at all. However, the phenomenological thought has been one resources behind the embodied ideas of cognitive science. In Varela, Thompson, and Rosch's theory of enaction, the phenomenological inspiration is evident, and so is in Noë's explanation of the sensorimotor theory of perceptual consciousness.

According to phenomenological philosophy, embodiment has two meanings: the body can be seen as a lived, experiential structure; it can also be seen as milieu of cognitive mechanism [2].

This basic distinction suggests that we can understand our body in two different ways: it can be understood as an objective body, and it can be understood as a lived subjective body. From third-person perspective of an observer, our body is seen as an objective body, while from the first-person perspective of the self, the body is experienced as a lived body. Standard cognitive science reduces embodiment to objective measures, for instance, it reduces our body to something that can be represented in computational programs. Such understanding ignores embodiment from the lived first-person perspective. Enactive theorists of the mind typically understand embodiment from a lived first-person perspective. Noë's sensorimotor theory of cognition is one case. According to Noë, cognition is not just happened in the brain. The lived body also plays a constitutive role in our cognition. It structures our experience of the world, and it is in this way that our body becomes a constitutive part of cognition. Thus, Martiny believes that Shapiro does not fully grasp the full meaning of the phenomenological understanding of embodiment, and following Andy Clark's functionalism and Wilson's wide computationalism, he concludes that embodied cognition loses in the theses of conceptualization and constitution. Martiny [21] concludes that embodied cognition represents a truly new paradigm of cognitive science and forms a new revolution of cognitive science.

However, the phenomenological understanding of embodiment is in a dual mode: lived, experiential body and objective body. The experiential body is experienced from first-person perspective and the objective body is from the third-person perspective. Where does the first-person perspective take place? The answer is that it happens in the brain. Recall Rowlands' dual understanding of intentionality: the empirical mode and the transcendental mode. The empirical mode of mind supervenes on the transcendental mode of mind. Those causal processes that constitute the transcendental mode of revealing are not necessarily located in the brain, and many of them are in the world. Therefore, in principle, a cognitive process can extend beyond the brain and beyond the body. However, Rowlands only lets the transcendental mode extend beyond the brain and the body. As already pointed out, this constitutes the main mind, i.e., the phenomenological mind still in the brain. Thus, we think that both Rowlands and Martiny do not give a good explanation of where our real cognition or mind is embodied or extended.

\section{Conclusion}

In a word, up to now, though transcranial cognition has not been a real Copernicus style revolution in cognitive science relative to traditional standard cognitive science, it greatly develops its scope and theory. Ongoing research within transcranial cognition may challenge this conclusion, but for now, our conclusion is reasonable. Transcranial cognitive science does not completely destroy the boundary of standard cognitive science. Thus, if we negate standard cognitive science or replace it because it does not emphasize the function of the body and environment in cognition, we may be in the wrong direction. Of course, when we say transcranial cognition is not a Copernicus style revolution, we do not deny the significance of the research of transcranial cognitive science. In a relatively larger frame of cognition, transcranial cognition can be seen as a complement to traditional standard cognitive science. The standard cognitive science pays much attention to informational processing and computing in the brain and practically neglects the role of the body and environment in cognition, while transcranial cognition research emphasizes the function of the body and environment in cognition and thus can supplement the defect of traditional cognitive science. Therefore, combining transcranial and standard cognitive science together can provide a better understanding of the essence of cognition and the mind. 


\section{Acknowledgements}

This paper is supported by the Planning Office of China Philosophy and Social Science Foundation. The project number is 14ZBD171.

\section{References}

[1] M. Rowlands. The New Science of the Mind: From Extended Mind to Embodied Phenomenology. Cambridge, MA: The MIT Press, 2019.

[2] F. Varela, E. Thompson, and E. Rosch. The embodied mind. Cambridge, MA: MIT Press, 1991.

[3] A. Clark and D. Chalmers. The extended mind. Analysis, 1998, $58,10-23$.

[4] G. Lakoff and M. Johnson. Philosophy in the flesh. New York: Basic Books, 1999.

[5] A. Noë. Action in perception. Cambridge, MA: MIT Press, 2004.

[6] F. Adams and K. Aizawa. The bounds of cognition. Oxford: Blackwell, 2008.

[7] M. Aydede (Eds.). Cambridge handbook of situated cognition. Cambridge: Cambridge University Press, 2009.

[8] L. Shapiro. Embodied Cognition. New York: Routledge, 2010.

[9] J. Stewart, O. Gapenne, and E. Di Paolo. Enaction: Toward a New Paradigm for Cognitive Science. Cambridge, Mass.: MIT Press, 2011.
[10] D. Hutto and E. Myin. Radicalizing Enactivism: Basic Minds Without Content. Cambridge, MA: MIT Press, 2013.

[11] D. Hutto and E. Myin. Evolving Enactivism: Basic Minds Meet Content. Cambridge, MA: MIT Press, 2017.

[12] M. Johnson. Embodied mind, meaning, and reason: how our bodies give rise to understanding. Chicago: The University of Chicago Press, 2017.

[13] S. Gallagher. Enactivist interventions: rethinking the mind. Oxford, UK: Oxford University Press, 2017.

[14] A. Jasanoff. The biological mind: how brain, body, and environment collaborate to make us who we are. New York, NY: Basic Books, 2018

[15] G. Colombetti. The Feeling Body: Affective Science Meets the Enactive Mind. Cambridge, Massachusetts: MIT Press, 2013.

[16] Z. Radman (eds.). The Hand, an Organ of the Mind. Cambridge, Massachusetts: MIT, 2013.

[17] B. Huebner (eds.). Macrocognition. Oxford: Oxford University Press, 2014

[18] M. Cappuccio, T. Froese (Eds.). Enactive Cognition at the Edge of Sense-Making. Palgrave Macmillan, 2014.

[19] J. Kiverstein, Andy Clark. Introduction: Mind Embodied, Embedded, Enacted: One Church or Many? Topoi, 2009, 28: 17.

[20] R. Menary. Introduction to the special issue on 4E cognition. Phenom Cogn Sci, 2010, 9: 459-463.

[21] K. M. Martiny. Book review of Lawrence Shapiro's Embodied Cognition. Phenom Cogn Sci, 2011, 10: 297-305. 